\title{
INFORMATION LITERACY IN KENYA
}

\author{
Khushbu Tilvawala \\ The University of Auckland \\ Information Systems and Operations \\ Management \\ Owen G. Glenn Building \\ Auckland, New Zealand, 92019 \\ k.tilvawala@auckland.ac.nz
}

\author{
Michael D. Myers \\ The University of Auckland \\ Information Systems and Operations \\ Management \\ Owen G. Glenn Building \\ Auckland, New Zealand, 92019 \\ m.myers@auckland.ac.nz
}

\author{
Antonio Díaz Andrade \\ Auckland University of Technology \\ AUT Business School \\ Business Information Systems \\ Auckland, New Zealand, 92006 \\ antonio.diaz@aut.ac.nz
}

\begin{abstract}
There are a growing number of information and communications technologies (ICT) initiatives in developing countries. These initiatives are usually undertaken on the basis that they are important for social and economic development. However, one barrier to the efficient utilisation of ICT in developing countries is the relatively low level of information literacy. Without the ability to manipulate and use information effectively, investments in ICT-for-development projects may be unsuccessful. In this research project, three ICT initiatives in Kenya are analysed in the light of the dimensions of information literacy. Implications for other developing countries are discussed.
\end{abstract}

Keywords: Information and communications technology, information literacy, developing countries, Kenya

\section{INTRODUCTION}

The information age has led to a shift in the global economy's focus from physical resources to the way information is manipulated (Castells, 2000; Drucker, 1969; Machlup, 1962). ICT has become the major driving force behind this shift. The challenge of keeping up with the information economy particularly affects developing countries. Although many developing countries still struggle with the provision of basic services like clean water and electricity, many are increasingly looking to ICT for development projects to improve their social and economic development (Shih, Kraemer, \& Dedrick, 2008; Walsham, Robey, \& Sahay, 2007).

However, one barrier to the efficient utilisation of ICT in developing countries is the relatively low level of information literacy. Without the ability to manipulate and use information effectively, investments in ICT-for-development projects may be unsuccessful. In fact, some scholars have suggested that the digital divide between the developed and developing world has widened because of the lack of information skills in developing countries (Dewan, Ganley, \& Kraemer, 2005). Without information literacy, developing nations may continue to underutilise the technology that is provided (Pejova, 2002), resulting in a waste of resources with potentially serious repercussions for their development.

We take the view, therefore, that achieving development through ICT is not just a matter of providing access to ICT tools. Rather, efforts should also be made to enhance 
information literacy, which provides the ability to manipulate and use information effectively. Hence, the purpose of this paper is to propose a theoretical framework on information literacy, in order to understand and evaluate three ICT for development initiatives in Kenya.

The paper is organised as follows. The next section presents a theoretical discussion on the concept of information literacy and explains the relationship between information literacy and ICT. The data collection and method of analysis is described in the third section. The fourth section provides background information on Kenya, the current status of ICT usage in general, and information literacy in particular. The analysis of the findings is presented in the fifth section. We conclude by presenting suggestions for improving information literacy in Kenyan ICT initiatives along with implications for other developing countries.

\section{INFORMATION LITERACY}

While we agree with Postman's (1990) claim that the information age began with the invention of the printing press, we believe that information technology has had a major impact in society during the last few decades. We have moved into a "post-industrial society" - where the service sector dominates the economy (Bell, 1973) - and to an "informational society" (Castells, 2000)- where "information generation, processing, and transmission become the fundamental source of productivity and power" (Castells, 2000, p. 21). In this new era, information literacy has become a fundamental skill.

\subsection{Defining Information Literacy}

The importance of the concept of information literacy has been recognised by several researchers and different definitions of information literacy in various contexts have been put forward. The first definition of information literacy, to the best of our knowledge, came from the American Library Association (ALA): the ability to recognise when information is needed as well as the ability to locate, evaluate and effectively use it (Carpenter, 1989, as cited in Plotnick, 1999). Doyle (1992) emphasises diversity in the origin of information and defines information literacy as the ability to access, evaluate and use information from a variety of sources.

From an educational perspective, Bruce (2003) defines information literacy as "the ability to access, evaluate, organise and use information in order to learn, problem-solve, make decisions in formal and informal learning contexts, at work, at home and in educational settings" (p. 4). Lenox and Walker (1993) provide guidelines for preparing information literate citizens. They recommend that teachers should shift their focus from product to process, recognise and accommodate diverse styles of acquiring information, and integrate information seeking into a learner-based curriculum that helps students to understand information as a commodity and the issues surrounding access. Similarly, Ralph (1999 as cited in Bruce, 2003, p.8) considers information literacy as a "key to lifelong learning", which includes computer literacy, information technology literacy, library skills, information skills and learning to learn.

The concept of information literacy has been compared with other types of literacy. For instance, Stern (2002) proposes a literacy spectrum: alphabetic literacy (i.e., being able to write), functional literacy (i.e., being able to read and write), social literacy (i.e., being able to communicate in a cultural context), information literacy (i.e., being able to locate, critically evaluate and use information) and digital information literacy (i.e., being able to apply information literacy in the digital environment). Warschauer (2004) recognises information literacy as part of the electronic literacy spectrum, which includes computer literacy - the ability to operate a computer.

For this research project, we adopt the definition of information literacy as provided 
by UNESCO's Information For All Programme (IFAP): information literacy is the capacity of people to recognise their information needs; locate and evaluate the quality of information; store and retrieve information; make effective and ethical use of information and apply information to create and communicate knowledge (Catts \& Lau, 2008). This definition is comprehensive because it entails all the information skills discussed above and most importantly highlights the power granted to the individual by being information literate.

Figure 1 below depicts the different aspects of information literacy contained in UNESCO's IFAP's definition. It also represents an analogy: information literacy can be seen as a flower made up of several petals, where it will still be a flower even when some petals are missing, but will not be perfect.

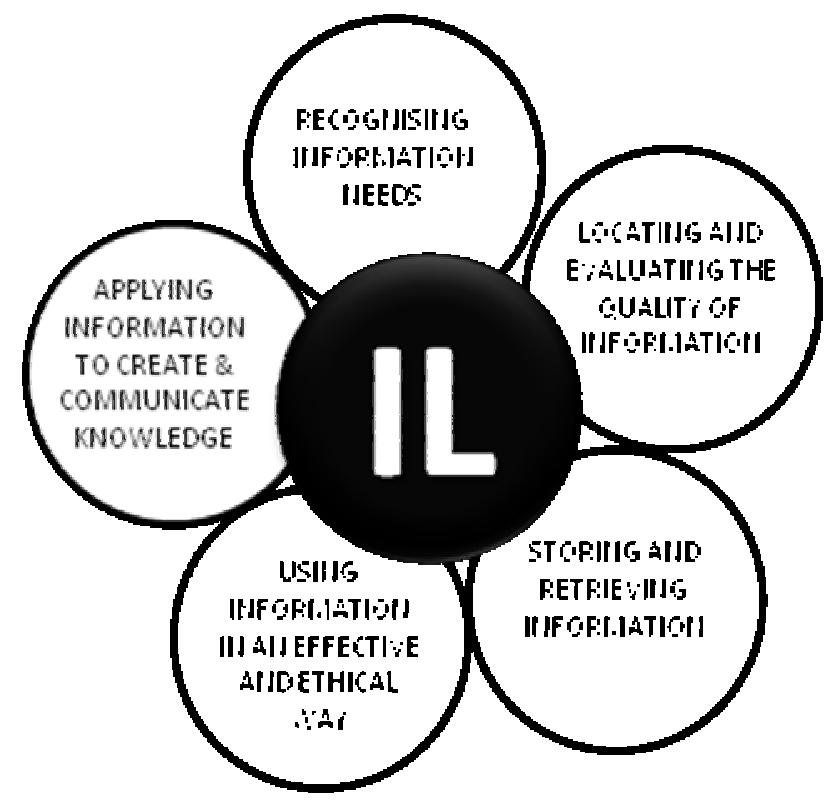

Figure 1. Different aspects of information literacy (Adapted from Catts and Lau 2008)

In Figure 1 above, 'recognising information needs' refers to the capacity of an individual to be aware that information is required to solve or address a certain task. Catts and Lau (2008) state that this awareness is not a static capacity but one which needs to be applied to every arising situation. The aspect of 'locating and evaluating the quality of information' entails two parts: locating information - the ability of an individual to know where to search for the required information based on the context - and 'evaluating the quality of information', which goes hand in hand with locating it - the ability to assess accuracy, credibility and reliability of the obtained piece of information. The capacity to 'store and retrieve information' can be related to different contexts: whether it is information about one's culture and heritage, business records and technical know-how, or storing one's personal contacts. The 'effectiveness of information use' represents the capability of using information optimally in problem solving and/or critical thinking, while the 'ethical use of information' entails using information in a way that does not affect other people's rights. The 'ability to create and communicate knowledge' is the ultimate product of information literacy since it enables knowledge creation.

There is no doubt that the spread of ICT tools has made information more easily available (Arunachalam, 2002; Postman, 1990). However, in order to make the best use of that information, people need to be information literate. ICT tools facilitate the storage, reception and transmission of information, extending its reach, but the process of processing that information requires information literacy skills. Processing information is a cognitive process that only human beings can perform (Walsham, 2001). For instance, electronic 
databases are nothing more than another source of information - no more and no less than an encyclopaedia; it is the user's abilities that make the difference when accessing them. That is why developing ICT skills without enhancing information literacy is of little help; they both should be developed in conjunction with each other (Catts \& Lau, 2008). Ultimately, it is information literacy that informs people's practices when accessing technological tools (McMahon \& Bruce, 2002).

There are some efforts underway that are directly or indirectly tackling the issue of information literacy around the world. For instance, the Sultanate of Oman has implemented a policy whereby the provision of ICT tools is accompanied by a curriculum aiming at developing information skills. In the same way, Estonia has pursued information literacy programs through enhanced information and library professional education (Pejova, 2002), while the Chinese government has designed a programme that emphasises the development of information literacy skills in public schools. In a different approach, the Egyptian government introduced ICT along with the aim of promoting information literacy (Warschauer, 2004).

\section{MeTHODOLOGY}

Our analysis is mainly based on secondary data, which includes reports, government websites and demographic information. In addition, the first author, who is a Kenyan researcher, held brief interviews with two officers at the Kenya ICT Federation (KIF), a private organisation that influences ICT policy making. Mr. Marcel Werner and Ms. Elina Kabiru, the chairman and the secretariat at KIF respectively, provided us with data and documentation about the current status and future plans of ICT in Kenya.

We cross-checked the data received from different sources in order not only to corroborate the information but also to get a good understanding of initiatives taken in Kenya regarding information literacy and the use of ICT tools. Our analysis was conducted on three projects currently underway in Kenya. These projects are explained next.

\subsection{NEPAD - New Partnership for Africa's Development}

The New Partnership for Africa's Development (NEPAD) e-schools initiative, launched in June 2003, is a multi-country, multi-stakeholder, continental project aiming at improving education through the use of ICT applications and the internet in primary and secondary schools in Africa. Kenya is among the nine African countries where the project has been rolled out and 100 schools have now been completed. In Kenya, the project is funded by Oracle, Microsoft and the Ministry of Education. The actual project roll out was preceded by a successful demo project that equipped six secondary schools with state-of-the-art ICTs and provided teacher training and learning content (Farrell, 2007). NEPAD e-schools' objective is "to provide ICT skills and knowledge to primary and secondary school students that will enable them to function in the emerging Information Society and Knowledge Economy" (NEPAD e-Africa Commission, N.D.). The NEPAD commission has created a partnership forum known as Information Society Partnership for Africa's Development (ISPAD). Most of the companies participating in the NEPAD e-schools are ISPAD members.

For this research, we focus our analysis on Kikambala School, which is under the Kenyan government's responsibility. According to the NEPAD partnership model, the government addresses the core components of the project which include appointing and supporting structures in the country necessary for planning and implementing, managing the entry and safety of equipment for the project as well as providing a favourable ICT regulatory environment. Of special relevance for this research, it is the government ensuring schools readiness for the project by training teachers and developing the content and curriculum. 


\subsection{KENET - Kenya Education Network Trust}

Kenya's Education Network Trust (KENET) is a research and education network that promotes the use of ICT in teaching, learning and research in higher education institutions in Kenya (Farrell, 2007). The project was launched in 1999 and the KENET Trust was formed in October 2000 by five founders - a combination of private and public institutions. It initiated from a bilateral agreement between the Kenyan and the United States governments to implement the Leland Initiative, by which the Kenyan government committed to exploring internet pricing reforms plus the linking of Kenyan universities to the internet. KENET is currently funded by the Kenyan Ministry of Education and the ICT Trust.

KENET consisted of 22 tertiary institutions countrywide by 2006. KENET's ultimate goal is the production of knowledge by fostering an information culture supported by ICT (Kyalo, 2005). While KENET's focus is on tertiary institutions, the project also envisions making the created knowledge available to the rest of the population. KENET's management model is comprised of three elements: 1) a human resource plan to manage the linkage among the participating tertiary institutions; 2) a financial plan to ensure sustainability; 3 ) a governance structure for the management of the system and its resources (Thairu, 2003, as cited in Nwagwu \& Abanihe, 2006).

\subsection{Pasha Centres}

The Pasha Centres project originated from the Kenyan government's recognition that ICTs have been centred mainly in the urban areas, resulting in glaring disparities between urban and rural areas in the distribution of ICT facilities (Kenya ICT Board, 2009). The project, initiated in 2008 by the Kenya ICT Board and funded mainly by the World Bank, aims at providing a suite of services to the public, especially those in the rural areas via computers connected to the internet. It is expected that by end of 2009, there will be at least 27 operational centres in rural areas (Balancing Act News, 2009).

Ms. Kabiru, who referred us to the project, said that it is about "creating awareness" or "to inform" (the meaning of pasha in Swahili), where around 1500 youths are being trained to run information centres countrywide, especially in the rural areas. Currently, the number of candidates to be trained stands at 7,000 (Capital Group Limited, 2009); so far, the project has trained 82 people in five centres across the country (Kags, 2009). Some of the services include health information, market price, employment opportunities - both directly and indirectly through the economic activities the centres generate - and government services e.g., National Social Security Fund (NSSF) statements, driving license application forms and police abstracts (Kenya ICT Board, 2009).

The Kenya ICT Board wants the centres to become an essential part of people's daily lives by creating opportunities for them. Availability of local entrepreneurs, relevant services for local people and a demand for those services are the key success factors for the project. Working with local computer enthusiasts, who know the needs and wants of the rural communities, would contribute to the project success; they can become "the focal points in their communities" in the words of Mr. Kukubo, the CEO of the Pasha Centres (Capital Group Limited). To complement the Pasha Centres, the Kenya ICT Board also has a scheme called TANDAA to encourage the generation of local content in Kenya (Kags, 2009).

There are three types of Pasha Centres and all provide services through a cyber café training centre type platform. The basic level centre has connectivity through four to five laptops housed alongside a retail outlet as a subsidiary business. The standard level centre has six laptops and a media room with multi-media equipment for audio-visual work; it also has an IT training room, offers VoIP (Voice over the Internet Protocol) calling services and provides wireless connection. The advanced level centre has an interview room, a coffee shop and a health pod in addition to all the services provided in the basic and standard centres above (Balancing Act News, 2009). 
The aforementioned projects are analysed vis-à-vis the theoretical framework presented in Figure 1.

\section{KENYA, ICTS AND INFORMATION LITERACY}

Despite Kenya being a major hub for trade and finance in East Africa, the country's high reliance on primary goods, political instability and high corruption have inhibited the country's economic development. Kenya's GDP growth rate had been quite steady from 2003 until 2007, after which it dropped drastically to from $7.1 \%$ in 2007 to $1.7 \%$ in 2008 (Oparanya, 2009), mainly due to the post election chaos in early 2008.

As most of developing countries, Kenya shows a high disparity in wealth distribution. Kenya's Gini coefficient has been fluctuating over the past two decades with an improvement from 0.57 in the 1990s to 0.425 in 2000 but back to 0.57 in 2004 (Farrell, 2007; UN Habitat, 2008). Kenya's human development index was 0.532 in 2006, which ranked Kenya 144th out of 179 countries (UNDP, 2008). In 2007, the country's ranking dropped to 152nd out of 177 countries (Farrell, 2007). Kenya's population is 38.5 million.

\subsection{ICT in Kenya}

Telecommunication services in Kenya were introduced in 1977 and managed as part of a regional network with neighbours Tanzania and Uganda. Since then, the ICT sector has been continuously growing, greatly influenced by global trends. The fastest growing and most popular ICT in Kenya is mobile phones. At present, there are three mobile service providers who have enabled various mobile services (e.g. mobile banking). The reliance on mobile communication and services was well reflected during the election chaos in January 2008 where people used pre-paid phone cards as a currency by trading them for food and medicine (Zephoria, 2008). In fact, the number of mobile subscribers increased to from 9.3 million in 2007 to 12.9 million in 2008 (Oparanya, 2009).

As regards internet, middle-class residences have internet access either through their fixed lines or through wireless internet services. There were 3,000,000 in 2008 as compared with 200,000 internet users in 2000, which represents an impressive leap on internet penetration from just $0.7 \%$ in 2000 to $7.9 \%$ in 2008 (Miniwatts Marketing Group, 2008).

Currently, the Kenyan government considers the adoption of ICTs as a key step in bridging the digital divide (Wims \& Lawler, 2007). As a result, there are several projects in place to promote the use of and investment in ICTs (PKF Consulting Ltd. \& International Research Network, 2005).

\subsection{Information Literacy in Kenya}

The Kenyan government has stated that "the achievement of an information-based society is one of the main priorities... in order to realise national development goals and objectives for wealth and employment creation" (Poghisio, 2008). Similarly, information literacy is a concept that has been recognised as a development enabler in Kenya. The government considers education the sine qua non condition for acquiring ICT skills in order to create dynamic and sustainable economic growth (Wims \& Lawler, 2007). The quality and efficiency of ICT application in Kenya can only be achieved by means of capacity building through research and development, which are elements of information skills (Kandiri, 2006). Similarly, it has been recognised that information literacy is essential for national development (Kenya National Bureau of Statistics, 2007).

Ayoo and Otike (2002) take a very critical stance and maintain that the formulation of an information policy in Kenya is hampered by the lack of information skills, mainly among top policy makers, which results in making the wrong choices of ICTs. Information policy should be supported by providing education, running literacy programmes and training with the participation of all information stakeholders: the government as information generating 
agents, the information professionals as information processors and disseminators and citizens as the information consumers (Kamar, 2006). The ICT and Education survey reveals the need to address information literacy when implementing ICTs in education, mainly due to a deficit in human resource capacity (Farrell, 2007).

\section{Findings AND ANALYSIS}

In the following sections, we present the findings and conduct the analysis of the aforementioned Kenyan ICT initiatives.

\subsection{NEPAD's Kikambala e-School}

In addition to providing information technology and internet for its students, Kikambala School is the only one in Africa that links up all schools in the country via the internet to share information on education, technology and health standards. The add-on project was supported by the Sun N Sand Beach Resort, a private organisation in Mombasa, where a wireless network with a radius of $50 \mathrm{~km}$ has been set up to facilitate the sharing of information. As a result, teachers in rural isolated schools can now exchange information with colleagues from other schools and access various educational materials to prepare their lessons. Students from these interconnected schools consider themselves very lucky for having access to computers and the internet and believe they can do "everything" with it (Marete, 2006).

The fact that teachers exchange information, especially on education and health, is an indication that they are able not only to recognise their information needs but also to locate the needed information. Teachers have demonstrated they have the appropriate knowledge to know where to seek information and guide their students in this process. Furthermore, sharing the information after locating it from the internet will demand skills to store and retrieve information. This storing and retrieving information is more than just computer skills; because the teachers share this information, they will have an understanding of what information needs to be saved for use in the future and how it links to other information for the purpose of enhancing the course and teaching content. Optimising the use of information sought and saved in the past and further shared among various institutions also means that the information is being used effectively.

In addition to ICT training for both teachers and students, the former have also received training in content and curriculum development as well as community involvement. About 33 teachers have learnt how to use email as well as make reports on MS Access ${ }^{\circledR}$ and presentations on MS PowerPoint ${ }^{\circledR}$ (Marete, 2006). Mr Walter Okello, a senior teacher, believes that these skills will not only make his work easier but also make it more interesting for the students. When teachers develop either reports or presentations, they are selectively and systematically organising information, which demonstrates their ability to store and retrieve information and use information effectively. When they gather course contents and materials for curriculum development, they are making use of their skills to recognise information needs and locate appropriate information.

Although the emphasis seems to be on the technology and its capabilities, it seems that students and especially teachers have increased their information literacy skills by the use of technological tools as a result of NEPAD's e-schools initiative.

\subsection{KENET}

KENET initiative is mainly focused on technical skills for supporting the infrastructure and ensuring reliable connectivity between the participating institutions; clearly, information skills are not a priority. As a consequence, both students and teachers of the tertiary institutions under this project markedly improved their abilities to use basic computer 
programs (Kyalo, 2005). However, there are certain elements within this initiative that allow us to see how aspects of information literacy are being addressed.

For instance, educational software supplied by the various consortia was enthusiastically received by the teachers. They claim that it allows them to produce their own learning materials and are keen to explore similar software tools. This outcome of the project provides positive indications for developing skills to recognise information needs. In order to produce learning content, the teachers have to understand students' information needs and the types of content that will improve their learning process. And producing content also entails the creation of learning material to be transferred to students, which helps cultivate the skills to apply information to create and communicate knowledge.

In terms of production and sharing, content has being generated and exchanged through collaborations formed among the institutions. The information flow and collaborations between faculties are based on a piloted and tested collaboration model for content delivery. The collaboration model requires that institutions accumulate $40 \%$ of their content requirements internally and fill the remaining $60 \%$ with content shared between other institutions in the national network. The model also enables people outside the network to access any information they need (Kyalo, 2005). This collaboration and sharing of information improves the skill to both recognise information needs in order to develop the content, and locate the required information. The overall concept in the collaboration model shows that there is an underlying intention to make effective use of the information or content material.

\subsection{Pasha Centres}

At the heart of the initiative is to develop services based on the information needs of local people. The entrepreneurs that represent their communities will therefore be the medium to realise the needs of people first in order to provide them with services that they can benefit from. The recognising information needs aspect of information literacy is therefore addressed here. The entrepreneurs will also have linkages with other entrepreneurs in the urban areas and the internet to further locate the information required by the community. It reveals that information locating skills are also inherent in the activity. The information locating skills of the community members coming to the centre may also be addressed, whereby the entrepreneurs help them locate the required information through the internet.

The TANDAA scheme, which complements the Pasha Centres project, aims at enabling local people share their knowledge via the internet. This activity shows that there is an attempt to use information effectively by making it comprehensible to all the populace. As Mr. Marcel Werner reasons, digitising and making information in native languages contributes to the development of information skills when teaching ICT skills.

\section{$5.4 \quad$ Summary}

Table 1 illustrates the three initiatives we analysed and summarises the aspects of information literacy that each one of them addresses. The various aspects are represented by a letter: Recognising information needs (R); Locating and evaluating the quality of information (L); Storing and retrieving information (S); Effective and ethical use of information (E); and Applying information to create and communicate knowledge (A). 'High' in the table means that the information literacy aspect is being addressed by the initiative to a great extent. 'Medium' means that the information literacy aspect is partially addressed. 'No Evidence' means that there is no data to support that the aspect of information literacy is being addressed. 
Table 1. Information skills addressed by ICT initiatives

\begin{tabular}{lccccc}
\hline Information Literacy Initiative & \multicolumn{5}{c}{ Information Skills } \\
& \multicolumn{1}{c}{ L } & S & E & A \\
NEPAD & High & High & High & Medium & No evidence \\
KENET & High & Medium & No Evidence & Medium & High \\
Pasha Centres & High & Medium & No Evidence & No evidence & No evidence \\
\hline
\end{tabular}

\section{CONCLUSION}

The purpose of this paper has been to propose a theoretical framework on information literacy, in order to understand and evaluate three ICT for development initiatives in Kenya. This was especially appropriate in the local Kenyan context, given that in 2008 the Kenyan government publicly acknowledged the importance of achieving an "information based society" to realise national development goals. Therefore, this research has analysed how information literacy is being addressed by the three ICT initiatives currently underway in Kenya.

Although the analysed initiatives were mainly focused on ICT and the development of ICT skills, the concept of information literacy is implicit to larger or lesser degree initiatives in all of them. When we analysed the initiatives against the theoretical framework proposed earlier in this paper, we found that none of them address all the information literacy dimensions showed in Figure 1. Only one aspect of information literacy out of the five was perceivable at a high degree in all the initiatives: to recognise information needs. Hence, while the Kenyan Government has taken the first step to developing information literacy, much more work needs to be done.

Our findings suggest that the parties in charge of the analysed initiatives can enhance information literacy by:

1. Communicating the importance of information literacy. Our research indicates that most Kenyans are not aware what information literacy or information-based societies mean. This information should be provided in various Kenyan vernaculars.

2. Promoting the development of information literacy-based curricula for ICTs in education. Alongside the development of appropriate content, pedagogical practices should be aimed at developing the information literacy by the design of education policies and strategies that address the dimensions shown in Figure 1.

In addition to the aforementioned suggestions specific to the Kenyan context, this paper provides an analytical framework for other developing countries willing to assess the presence of information literacy initiatives in ICT for development projects.

This paper provides avenues for future research. Firstly, the findings from this research could be reassessed by analyzing different future projects in Kenya or by revisiting the existing projects at a later date. Secondly, we encourage other researchers to analyze information literacy in other developing countries.

In conclusion, we suggest that information literacy should be embraced by all developing societies, while maintaining their own cultural identity. Considering the increasing importance of the information economy, information literacy skills are vital if developing countries are to make the best use of ICT for development initiatives.

\section{REFERENCES}

Arunachalam, S. (2002) Reaching the Unreached: How Can We Use Information and Communication Technologies to Empower the Rural Poor in the Developing World 
through Enhanced Access to Relevant Information? Journal of Information Science, 28, 6, 513-522.

Ayoo, P. \& Otike, J. (2002) Factors Hampering the Formulation of a National Information Policy in Kenya, Library Review, 51, 7, 350-357.

Balancing Act News (2009) Balancing Act News Update. Kenya's Pasha Centres Initiative Seeks a New Way to Reach Out into Un-serviced Areas http://www.balancingactafrica.com/news/back/balancing-act 456.html.

Bell, D. (1973) The Coming of Post-Industrial Society: A Venture in Social Forecasting. New York: Basic Books.

Bruce, C. (Producer) (2003) Seven Faces of Information Literacy: Towards Inviting Students into New Experiences. http://crm.hct.ac.ae/events/archive/2003/speakers/bruce.pdf

Capital Group Limited (2009) Dawn of a New Era http://www.capitalfm.co.ke/business/Featured/Dawn-of-a-New-Era-2165.html

Castells, M. (2000) End of Millennium - The Information Age: Economy, Society and Culture (2nd ed. Vol. 3) Malden, MA, USA: Blackwell Publishers.

Catts, R. \& Lau, J. (2008) Towards Information Literacy Indicators. Paris: UNESCO.

Dewan, S., Ganley, D. \& Kraemer, K. L. (2005) Across the Digital Divide: A Cross-Country Multi-Technology Analysis of the Determinants of IT Penetration. Journal of the Association for Information Systems, 6, 12, 409-432.

Doyle, C. (1992) Outcome Measures for Information Literacy within the National Education Goals of 1990: Final Report of the National Forum on Information Literacy. Washington, DC: US Department of Education.

Drucker, P. (1969) The Age of Discontinuity. Heinemann: Heinemann.

Farrell, G. (2007) Survey of ICT and Education in Africa: Kenya Country Report. Nairobi, Kenya.

Kags, A. (2009) TANDAA: All about Kenyan Content, http://www.tandaa.co.ke/

Kamar, N. (2006) Factors Hindering Effective Management of Government Information in Kenya. Paper presented at the WSIS Follow-up Conference on Access to Information and Knowledge for Development.

Kandiri, J. M. (2006) ICT Policy in Kenya and Ways of Improving the Existing Policy. In M.S.S.A.M. a. Uonbi (Ed.) Nairobi: University of Nairobi.

Kenya ICT Board (2009) Pasha Centres http://www.ict.go.ke/

Kenya National Bureau of Statistics (2007) Kenya National Literacy Survey Report. Nairobi, Kenya: Author.

KIF (2008) ICT Legislation for Prosperity and Economic Growth (Proposal) Nairobi: Kenya ICT Federation.

Kyalo, V. (Producer) (2005) The Kenya Education Network Experience (Opportunities, Challenges \& Lessons Learned) http://www.kenet.or.ke

Lenox, M. F. \& Walker, M. L. (1993) Information Literacy in the Educational Process. The Educational Forum, 52, 2, 312-324.

Machlup, F. (1962) The Production and Distribution of Knowledge in the United States. Princeton: Princeton University Press.

Marete, G. (2006) Doing IT: A First for Kenyan School Offering NEPAD E-classes. Afrika News. http://afrikanews.org

McMahon, C. \& Bruce, C. (2002) Information Literacy Needs of Local Staff in CrossCultural Development Projects, Journal of International Development, 14, 113-127.

Miniwatts Marketing Group (2008) Internet World Stats, http://www.internetworldstats.com/af/ke.htm

NEPAD e-Africa Commission (N.D.) Projects. NEPAD E-schools Initiative http://www.eafricacommission.org/projects/127/nepad-e-schools-initiative 
Nwagwu, W. \& Abanihe, I.I. (2006) Emerging Trends and Setbacks in e-Learning Networks in Africa. Journal of Information Technology Impact, 6, 2, 85-100.

Oparanya, W. A. (Producer) (2009) Kenya Economic Survey 2009 Highlights. http://www.cbs.go.ke/publications/ES2009MinisterPresentation.pdf.

Pejova, Z. (2002) Information Literacy: An Issue which Requests Urgent Action in Developing Countries and Countries in Transition. Paper presented at the UNESCO, the U.S. National Commission on Libraries and Information Science, and the National Forum on Information Literacy, for use at the Information Literacy Meeting of Experts. http://www.nclis.gov/libinter/infolitconf\&meet/papers/pejova-fullpaper.pdf,

PKF Consulting Ltd. \& International Research Network (2005) Kenya's Information \& Communications Technology Sector 2005. Nairobi: Export Processing Zones Authority.

Plotnick, E. (1999) Information Literacy, Definition of Information Literacy http://www.ericdigests.org/1999-4/information.htm

Poghisio, S. (2008) About Kenya ICT Board. Minister of Information \& Communications http://www.ict.go.ke/inner.php?cat=abtus

Postman, N. (1990) Informing Ourselves to Death http://www.frostbytes.com/ ujimf/informing.html

Shih, E., Kraemer, K.L. \& Dedrick, J. (2008) IT Diffusion in Developing Countries, Communications of the ACM, 51, 2, 43-48.

Stern, C. (2002) Information Literacy Unplugged: Teaching Information Literacy without Technology, http://www.nclis.gov/libinter/

UN Habitat (2008) State of the World's Cities 2008/2009 http://www.unhabitat.org/downloads/docs/presskitsowc2008/PR\%201.pdf

UNDP (2008) Human Development Report 2007/2008. The Human Development Index Going Beyond Income http://hdrstats.undp.org/es/2008/countries/ country fact sheets/cty fs KEN.html

Walsham, G. (2001) Knowledge Management: The Benefits and Limitations of Computer Systems, European Management Journal, 19, 6, 599-608.

Walsham, G., Robey, D. \& Sahay, S. (2007) Foreword: Special Issue on Information Systems in Developing Countries, MIS Quarterly, 31, 2, 317-326.

Warschauer, M. (2004) Technology and Social Inclusion: Rethinking the Digital Divide. London: The MIT Press.

Wims, P. \& Lawler, M. (2007) Investing in ICTs in Educational Institutions in Developing Countries: An Evaluation of their Impact in Kenya, International Journal of Education and Development using ICT 3, 1.

Zephoria (2008) Mobile Phone Credits as Currency in Kenya http://www.zephoria.org/thoughts/archives/2008/01/16/mobile_phone_cr.html 